\title{
PERCEPÇÕES ACERCA DE ADOLESCÊNCIA POR PARTE DE PROFESSORES DE CIÊNCIAS
}

\section{PERCEPTIONS ABOUT ADOLESCENCE BY SCIENCE TEACHERS}

\author{
Tatiana Marcondes ${ }^{1}$ \\ José Alves da Silva ${ }^{2}$
}

\begin{abstract}
Resumo: Discutimos percepções sobre adolescência de um grupo de professores de ciências que frequentaram um curso de extensão. Para tanto, realizamos uma pesquisa qualitativa em educação com foco no cotidiano escolar que incluiu como instrumentos de pesquisa: material proveniente de videogravação, produções dos professores e anotações da pesquisadora. Na análise, usamos algumas ideias de Moscovici para representações sociais. Constatamos percepções pouco divergentes em relação aos estereótipos de adolescentes difundidos socialmente, ainda que tenham ocorridos avanços (como o reconhecimento de características dos adolescentes, das referências etc.) em direção aos conceitos científicos trabalhados no curso. Esperamos maior atenção sobre adolescência na formação de professores de ciências, posto que, possivelmente, essas percepções estão presentes na forma com que os professores exercem seu trabalho.
\end{abstract}

Palavras-chave: Adolescência; Ensino de Ciências; Formação Continuada de Professores de Ciências.

\begin{abstract}
We discussed perceptions about adolescence of a Science teachers group who attended an extension course. Although, we conducted a qualitative research in education with a focus on school routine, which included as research tools: video recording material, teachers productions and the researcher`s notes. In this analysis, we used some of Moscovici`s ideas for social representations. We found slightly divergent perceptions in relation to adolescents stereotypes that are socially disseminated. Even though advances have occurred (such as the recognition of adolescents characteristics, references and etc.) towards the scientific concepts worked on that course. We expect greater attention on adolescence in the training of Science teachers, since these perceptions are present in the way that teachers exercise their work.
\end{abstract}

Keywords: Adolescence; Science Teaching; Continuing Education of Science Teachers.

\section{Diferentes compreensões de adolescência}

Este estudo discute adolescência na visão de professores de ciências. Trata-se, pois, de uma tentativa de fazer com que este tema adquira considerável relevância na área, dada a nossa crença de que é fundamental para um professor ou pesquisador da conhecer o assunto, de forma a ampliar o escopo de variáveis que merecem atenção presentes no processo de ensino-aprendizagem de conteúdos científicos. Apresentaremos, de início,

\footnotetext{
${ }^{1}$ Mestra em Ensino de Ciências e Matemática pela Universidade Federal de São Paulo (Unifesp), Diadema, SP, Brasil. E-mail: tatiana.tmarcondes@gmail.com.

${ }^{2}$ Doutor em Educação pela Universidade de São Paulo (USP). Professor orientador do Programa de PósGraduação em Ensino de Ciências e Matemática (PECMA) da Universidade Federal de São Paulo (Unifesp), Diadema, SP, Brasil. E-mail: josealves.unifesp@gmail.com.
} 


\section{Revista Brasileira de Educação em \\ Ciências e Educação Matemática \\ ISSN 2594-9179}

DOI: https://doi.org/10.33238/ReBECEM.2021.v.5.n.1.26083

algumas compreensões acerca do que é adolescência (de acordo com os nossos referenciats teóricos) e a concepção que adotamos sobre o tema. Em seguida, descrevemos nosso estudo e alguns dos resultados importantes do trabalho.

Tomada às devidas proporções, parece ser consenso entre as diferentes percepções, sejam elas sociais, biológicas, culturais, dentre outras, de que a adolescência é uma fase do desenvolvimento humano, distinta e intermediária entre infância e a vida adulta (PEREIRA, 2005). Contudo, essa é uma noção recente na história da humanidade. Segundo Ariés (1981), comportamentos típicos adolescentes são descritos há muito tempo. Entretanto, conforme este mesmo autor, a adolescência começa a se distinguir como uma fase de vida com características bem definidas somente no final do século XIX. Foi apenas no século XX que as várias transformações socioeconômicas que a civilização ocidental sofreu - como o estouro da Primeira Guerra Mundial (1914-1918) e o processo de urbanização a partir da metade do século XX - tornaram mais evidentes as ideias atuais sobre o tema. Dessa maneira, a adolescência, tal qual a compreendemos hoje, nem sempre existiu, sendo uma construção cultural e histórica (antes desses períodos mencionados, as modificações de natureza biológica presentes comumente no que chamamos hoje de puberdade já eram suficientes para caracterizar a entrada do sujeito na vida adulta, ou seja, já se passava da infância para a a idade adulta, sem que houvesse uma etapa intermediária (CALLIGARIS, 2000)). Os estudos modernos sobre adolescência, principalmente, oriundos da psicanálise relatam que essa fase da vida foi criada tendo a clareza da falta de reconhecimento do sujeito adolescente como um adulto completo. Isso gera transformações psíquicas como a chamada "crise de identidade", presente na obra de diversos estudiosos sobre o tema (CALLIGARIS, 2000; PEREIRA, 2005; SILVA, 2008; AMARAL, 2006; 2017). Calligaris (2000; p.15) em seu livro clássico sobre o assunto, aponta que é considerado um adolescente aquele(a):

1. que teve (sic) o tempo de assimilar os valores mais banais e mais bem compartilhados na comunidade (por exemplo, no nosso caso: destaque pelo sucesso financeiro/social e amoroso/sexual) (sic);

2. cujo corpo chegou à maturação necessária para que ele possa efetiva e eficazmente se consagrar às tarefas que lhes são apontadas por esses valores, competindo de igual para igual como todo mundo;

3. para quem, nesse exato momento, a comunidade impõe uma moratória.

A moratória, conceito amplamente desenvolvido na obra de Calligaris (2000), estaria presente nessa fase da vida, sendo um “tempo de espera” (p.15) em que há algumas restrições impostas pela sociedade aos adolescentes, as quais não são reconhecidas como típicas de crianças (já que os sujeitos possuem certo discernimento no campo das relações 


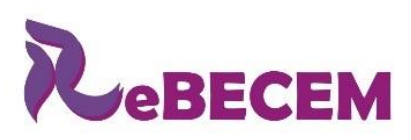

DOI: https://doi.org/10.33238/ReBECEM.2021.v.5.n.1.26083

amorosa/sexual e financeiro/social) e nem típicas de adultos. Assim, embora já tenham maturidade suficiente para atuarem em muitas atividades de maneira satisfatória, é-lhes colocada, pela sociedade, esta moratória, que lhes impede a permissão da execução de uma vida adulta. Segundo esse autor, acompanhado por outros teóricos no assunto (AMARAL, 2017; SILVA, 2008), esse período se associa a uma crise de identidade, pois o sujeito percebe que ficará sob a tutela de um adulto mesmo se sentindo preparado - pelo menos fisicamente - para atuar de forma plena na sociedade. A resposta que se obtém por parte dos adolescentes perante esse quadro é de "[...] raiva, ojeriza, desprezo e, enfim, rebeldia", conforme aponta Calligaris (2000, p.14). Além disso, segundo Gutierra (2003), a falta de dispositivos simbólicos que regulem a passagem da infância para o mundo adulto contribui enormemente para reforçar essa crise em tempos atuais. Pereira (2005) explica que esses dispositivos simbólicos são os rituais que ainda acontecem em algumas culturas para simbolizar o fim da infância e marcar o início da vida adulta, mas que se perderam em nossa sociedade. Assim, Gutierra (2003, p.29) esclarece que o ato de "adolescer" é o substituto desses rituais perdidos na atualidade.

Entretanto, como aponta Amaral (2006), tal crise de identidade não é necessariamente ruim, visto que é por meio dela que o sujeito construirá e definirá o seu projeto de vida afetivo e social (MARCONDES; SILVA, 2017). Ou seja, suas escolhas de parceiros (dimensão afetiva), sua profissão e seus ideais políticos (dimensão social) serão definidas, também, a partir de tal crise. Também é nessa fase da vida que as referências, em conjunto com a experimentação de papéis (PEREIRA, 2005), surgem como forte poder simbólico, as quais podem ser representadas por diversos atores do universo adolescente que podem lhes gerar inspiração, identificação ou desejo de seguilas. Para tanto, há desde artistas, personagens, esportistas ou outras figuras públicas, como também pessoas próximas como professores, parentes, vizinhos, além do próprio conhecimento - esse último caso, em particular, ocorre quando o adolescente percebe no próprio conhecimento uma importante ferramenta para aprender coisas novas, ou perceba que deter minado pode lhes ajudar a obter sucesso futuro.

É importante salientar ainda que, para a psicanálise, não há data precisa para o fim da adolescência. O consenso está somente no seu início, por volta dos onze anos de idade, na puberdade (período inicial da adolescência que ocorre após a infância no qual ocorrem: aparecimento dos caracteres sexuais secundários, rápido crescimento do corpo, surgimento do interesse sexual por outra pessoa e, sobretudo, a capacidade fisiológica plena do corpo para a reprodução; PEREIRA, 2005). Calligaris (2000) afirma que essa 


\section{Revista Brasileira de Educação em \\ Ciências e Educação Matemática \\ ISSN 2594-9179}

DOI: https://doi.org/10.33238/ReBECEM.2021.v.5.n.1.26083

falta de empatia, das dificuldades de concentração e de cálculos de consequência comumente presentes na descrição de comportamentos adolescentes.

Após esse conjunto de percepções sobre o tema, assumimos, neste artigo, que a adolescência é condicionada por fatores biológicos, psíquicos, culturais e sociais e que começa a partir da puberdade, mas que não apresenta data definida para terminar - como apontam diversos autores (CALLIGARIS, 2000; PEREIRA, 2005; AMARAL, 2006; SILVA, 2008, MARCONDES; SILVA, 2017; SILVA; FORATO, 2017). Além disso, levamos em consideração que adolescentes não são iguais entre si, embora tenham características comuns (SILVA, 2008), como a busca pela própria identidade.

Esses elementos identificados nas pesquisas sobre adolescência certamente afetam a relação dos adolescentes com os adultos, incluindo os professores. Dessa maneira, a subjetividade do professor e as relações que se estabelecem com o aluno na escola, sejam relativas à aprendizagem ou à afetividade, estão intimamente relacionadas. Além disso, há autores que apontam dificuldades em um professor especialista em determinada área do conhecimento - o de Ciências, inclusive - identificar-se como um professor de adolescentes (SILVA, 2013; GUTIERRA, 2003).

Por conta desse quadro, a presente pesquisa pretende lançar luz sobre as percepções de adolescência que professores de ciências trazem consigo, de forma a buscar indícios de como abordar o tema na formação inicial e continuada de professores de ciências. As formas com as quais pesquisamos encontram-se a seguir.

\section{Aspectos da metodologia}

Após definida a perspectiva desta pesquisa para as questões da adolescência, a intenção passou a ser como mapear as percepções $^{3}$ que professores de ciências apresentam quando instados a discutirem sobre o que é adolescência, a crise de identidade, as influências histórico-culturais associadas às biológicas, o papel das regras etc. Para alcançarmos esse objetivo, fizemos uma pesquisa qualitativa em educação

\footnotetext{
${ }^{3}$ Utilizamos o termo percepção como sendo: "organização e interpretação de sensações/dados sensoriais que resultam em uma "consciência de si e do meio ambiente", como uma "representação dos objetos externos/exteriores. Destacamos a interpretação como um fator importante: isso significa que não percebemos o mundo diretamente porque a nossa percepção é sempre uma interpretação desse mundo (MATOS; JARDILINO, p.27, 2016)". Esse termo difere de 'concepção' e de 'representação social', segundo esses autores.
} 


\section{Rebecem}

DOI: https://doi.org/10.33238/ReBECEM.2021.v.5.n.1.26083

(ANDRÉ; LUDKE, 1986) que, de modo geral, pode ser feita a partir de várias visões de mundo (LUDWIG, 2014). Em nosso trabalho, optamos por aquela mais ligada à fenomenologia, a qual, segundo André (2003, p.10) “[...] enfatiza os aspectos subjetivos do comportamento humano que os sujeitos atribuem aos acontecimentos e às interações sociais que ocorrem em sua vida diária". No entanto, como há diversos ramos da pesquisa qualitativa em educação que podem receber a alcunha de fenomenológica, adotamos os elementos que compõem a etnografia para amparar nossos procedimentos. Segundo André (1995), para a efetivação de uma pesquisa com elementos etnográficos, a observação participante e a análise de documentos são práticas tradicionalmente utilizadas. Por isso, neste trabalho, fizemos uso da observação (videogravação autorizadas pelos participantes da pesquisa e diário de bordo escrito pelos autores desse artigo) - explicaremos mais adiante)), de modo a contemplar a interação entre o pesquisador e o objeto pesquisado (ANDRÉ, 1995). Mais especificamente, no que tange à pesquisa qualitativa em educação com elementos etnográficos, adotamos a visão do cotidiano escolar como categoria teórica, na acepção proposta por André (2003), “[...] por meio da qual se vai conhecer as especificidades da experiência escolar diária" (p.9). Nessa concepção, o cotidiano não é, portanto, um "lugar de coleta de dados" (ANDRÉ, 2003, p.9) - não é um estudo no cotidiano, mas sobre o cotidiano.

Os estudos sobre o cotidiano, segundo André (2003), devem levar em consideração quatro dimensões intimamente ligadas:

a) Subjetiva/pessoal: "abrange a história de cada sujeito, manifesta no cotidiano escolar, pelas suas formas concretas de representação social, por meio das quais ele age, se posiciona, se aliena, se comunica" (ANDRÉ, 2003, p.16).

b) Institucional/organizacional: “A dimensão institucional age, assim, como um elo de ligação entre a práxis social mais ampla e aquilo que ocorre no interior da escola". Assim, a autora declara que: "Seu estudo vai exigir, então, [...] um estudo das representações dos atores escolares" (ANDRÉ, 2003, p.17; grifo nosso).

c) Instrucional ou pedagógica: Aqui, nesta dimensão, são englobadas as situações de ensino "nas quais se dá o encontro professor-aluno-conhecimento" (ANDRÉ, 2003, p.17).

d) Sociopolítica: "se refere ao contexto sociopolítico e cultural mais amplo, ou seja, aos determinantes macroestruturais da prática educativa" (ANDRÉ, 2003, p.18).

Para contemplarmos o papel dos participantes da pesquisa, fizemos uso da videogravação em todos os momentos do encontro, de modo a observarmos as percepções 


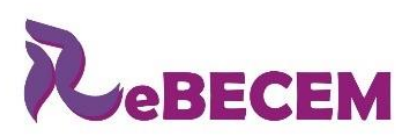

DOI: https://doi.org/10.33238/ReBECEM.2021.v.5.n.1.26083

(detalhadas mais adiante) sobre adolescência que surgiam ao longo do curso. Quanto à dimensão institucional/organizacional e instrucional ou pedagógica, por meio da análise das percepções dos participantes, tentamos observar as influências, por exemplo, políticas e sociais referentes à adolescência, bem como os valores embutidos nas falas, contemplando as influências indiretas e diretas que abarcam o cotidiano escolar. Já em relação à quarta dimensão (sociopolítica), para abrangê-la, destacamos o papel da sociedade pós-moderna (HABERMAS, 2002; LIPOVESTKY, 2005) nas percepções sobre a adolescência de nossos professores.

Para efetivarmos essa intenção, na prática, criamos um curso de extensão que pretendeu levar os conhecimentos sobre adolescência no contexto escolar produzidos na academia à comunidade externa, contribuindo para a formação de todos os envolvidos, inclusive dos próprios membros do campus de uma universidade pública situado numa cidade periférica da Grande São Paulo. No que se refere à pesquisa ${ }^{4}$, o curso foi elaborado com o objetivo de criar uma situação de cotidiano escolar, de forma a mostrar o quanto os elementos relacionados à adolescência (como crise de identidade, referências, papel das regras) poderiam ser decisivos no processo de ensino-aprendizagem em ciências, e no que a área de ensino de ciências poderia contribuir para que este período vivido pelos alunos fosse compreendido da melhor maneira possível pelos professores. A carga horária foi de vinte horas, consistindo em quinze horas presenciais e cinco horas reservadas para atividades extracurriculares. Para isso, professores de ciências, química, física e biologia inscreveram-se livremente e foram reunidos no primeiro semestre de 2017, todos os sábados do mês de maio (dias 06, 13, 20 e 27) e um do mês de junho (dia 03), somando cinco sábados, para discutirmos o assunto e os pontos associados a ele mencionados acima. O curso foi ministrado por um professor e por uma mestranda em ensino de ciências da Universidade, ambos autores deste artigo e, em sua realização, ocorrriam debates, leitura de textos sobre o tema e questionário de avaliação do curso a ser respondido pelos participantes. Neste trabalho, entretanto, destacaremos, com maior ênfase, os resultados obtidos na elaboração e no momento de apresentação de cada grupo para todos os participantes da sequência didática (ZABALA, 1998) ou do projeto juvenil (CARNEIRO, 2001). Cada grupo de três a quatro pessoas podia escolher livremente um tema de ciências e associá-lo às questões de adolescência trabalhadas no curso. Apenas uma pessoa fez individualmente. Ao todo, tivemos cinco sequências didáticas elaboradas

\footnotetext{
${ }^{4}$ A pesquisa foi submetida à aprovação pelo Comitê de Ética e Pesquisa (CEP) da Unifesp sob o número
} de Certificado de Apresentação para Apreciação Ética (CAAE): 66397117.0.0000.5505, sendo aprovada. 


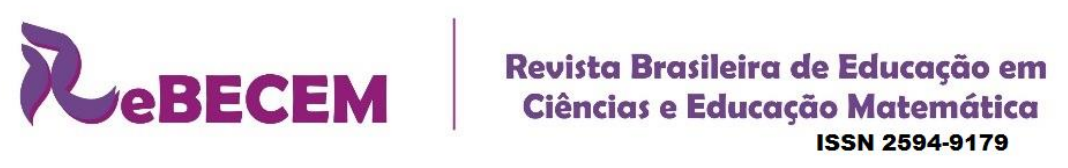

DOI: https://doi.org/10.33238/ReBECEM.2021.v.5.n.1.26083

e dois projetos juvenis ${ }^{5}$. Como queríamos registrar o cotidiano, escolhemos a videogravação para captá-lo, já que uma das tendências da etnografia é recorrer ao vídeo para coleta e análise dos dados (ANDRÉ, 1995). A filmagem foi feita por uma das pesquisadoras em todos os momentos do curso. Todos os encontros foram transcritos - $\mathrm{O}$ que nos gerou um excesso de material. Por isso, escolhemos determinados eventos críticos $^{6}$, conforme sugestão de Lima (2015), para transcrição, seguindo alguns critérios estabelecidos e com base nos referenciais teóricos adotados que serão explicados mais adiante.

\section{Análise e discussão dos resultados}

Para a análise dos dados, escolhemos trabalhar com a teoria das representações sociais (TRS), proposta inicialmente pelo psicólogo social romeno Serge Moscovici (1928-2014), sobretudo porque, acreditamos, poderíamos contemplar mais a dimensão subjetiva que enfatiza as representações dos sujeitos, proposta pelos nossos referenciais metodológicos sobre o cotidiano escolar. De acordo com Crusoé (2004), a TRS atua na dinâmica entre o conhecimento de senso comum e o científico. A autora diz que o conhecimento de senso comum não é um "disfuncionamento" (p. 107) do conhecimento científico. Mas, por ser conhecimento circunscrito, é diferente do segundo, pois busca a generalização e a operacionalização. Assim, ela afirma que a TRS “[...] é uma proposta científica de leitura do conhecimento de senso comum e, nesse sentido, preocupa-se com o conteúdo das representações” (p.107). Aqui cabe ressaltar que uma representação social é tudo aquilo que tem um significado para alguém, e este significado tem sempre um caráter social que é determinante para a compreensão dos processos simbólicos de condutas e de comportamento humano (MOSCOVICI, 2015). Dessa forma, as representações de algo ou alguém são determinadas na mente do sujeito, como base em elementos cognitivos, ideológicos, atitudinais, de valores, de crenças, de contexto social e histórico que se organizam para desvelar um significado da realidade cotidiana muitas vezes de forma inconsciente e subjetiva (MOSCOVICI, 2015). Por aí, podemos observar

\footnotetext{
${ }^{5}$ Os temas escolhidos pelos participantes da pesquisa foram: alimentação saudável, origem do universo, trânsito e álcool, aranhas, polímeros, drogas, reciclagem e preservação ambiental.

${ }^{6}$ Usamos, aqui, a definição de Lima (2015; p.4) para eventos críticos: "Podemos entender, então, eventos críticos como aqueles momentos que, de uma forma direta ou indireta, são importantes para pesquisa".
} 
DOI: https://doi.org/10.33238/ReBECEM.2021.v.5.n.1.26083

o quanto a TRS se aproxima da nossa opção metodológica que se fundamenta, em sua essência, na fenomenologia. Salientamos que, segundo Moscovici (2001), as representações sociais diferem de acordo com cada sociedade na medida em que são constituídas. Desse modo, os modelos de representação que formam a mentalidade de uma sociedade são diferentes dos de outras sociedades e culturas. Assim, as representações sobre adolescência e seus elementos que foram observadas nesse trabalho são próprias da realidade daquele cotidiano.

Para este mesmo autor, a realidade é dividida em dois universos: "o consensual e o reificado" (p.49). No universo consensual, estão expressas as atividades relacionadas ao senso comum. É nesse universo que se encontram as representações sociais - neste caso, o conhecimento é espontâneo. Já no universo reificado, segundo o autor, encontramse os conhecimentos e os saberes científicos que prezam pelo rigor, pela objetividade, pela racionalidade. Porém, Moscovici (2015) ressalta que esses dois universos se interrelacionam, além de serem próprios de determinada cultura, e são as ideologias que facilitam a transição de um universo para outro (transforma categorias consensuais em categorias reificadas). As representações sociais são criadas por dois mecanismos: por objetivação e por ancoragem, mas a ciência também contribui para a geração de tais representações, sendo ciência e representações sociais diferentes e complementares ao mesmo tempo. Moscovici (2015) afirma que, atualmente, as ciências também podem gerar representações.

A partir da TRS, analisamos o quanto as falas dos professores no curso e nas entrevistas se distanciaram ou não dos conceitos trazidos pelos nossos referenciais teóricos sobre adolescência, com destaque para Calligaris (2000), Pereira (2005), Amaral (2006; 2017), Gutierra (2003) e SILVA (2008; 2013). Portanto, ressaltamos que não fizemos uma pesquisa sobre representação social nos moldes já costumeiramente desenvolvidos na área de ensino de ciências ${ }^{7}$, visto que a TRS nos foi um aporte para a análise realizada a partir dos pontos de vista dos professores e dos referenciais teóricos e metodológicos que utilizamos. Seguindo a própria definição de Moscovici para reificação, chamaremos a percepção dos nossos referenciais acerca de cada elemento

\footnotetext{
${ }^{7}$ À medida que a TRS foi substancialmente desenvolvida, ficou mais clara a diferença entre percepções e representações sociais. De acordo com Matos e Jardilino (2016): "O estudo das representações permite que se analise o elemento simbólico dos relacionamentos e dos universos consensuais que surgem nas interações entre as pessoas. Os significados gerados, ao atribuir linguagem, valores e ideias comuns, evidenciam a dimensão social que se distingue da faceta individual das representações" (p.27). Escolhemos usar o termo percepção exatamente porque focamos na faceta individual manifestada pelos participantes em um grupo pequeno comparativamente ao universo efetuado nas pesquisas atuais de TRS.
} 
DOI: https://doi.org/10.33238/ReBECEM.2021.v.5.n.1.26083

Quando perguntada sobre o que é adolescência, Sandra diz que a adolescência tem uma faixa etária específica que começa e tem um fim definido. O professor pergunta qual é esta faixa, se há um término e ela resposde responde]:

- "Eu acho que (a adolescência) vai dos onze (anos de idade) até os vinte e um (anos de idade). Isso pra mim é um adolescente [...] eu fui adolescente até os vinte um!" (1º dia, gravação 1, trecho: 00:12:16 $00: 15: 26)$

[Flávio, ao ser também indagado sobre a definição de adolescência, diz que o adolescente não é mais criança, e Micheli o complementa dizendo que também não é adulto]:

- "Eu acho também que é uma fase que...que...que todos os adultos falam "você não é mais criança". Né (sic)?" (Flávio - 1ºdia, gravação 1, trecho 00:01:36 - 00:05:32);

- "Mas também não é adulto né (sic)? Aí fica esse conflito" (A sala balança a cabeça de modo afirmativo, parecendo concordar com Micheli). (Micheli - $1^{\circ}$ dia, gravação 1, trecho 00:01:36 - 00:05:32).

Quadro 1: Sobre a adolescência ser uma etapa da vida sem idade para acabar e sobre a falta de identidade que a caracteriza.

Fonte: Elaborado pelos autores com base nas videogravações, 2019.

Como pode ser observado, há considerável acordo entre os professores de que a adolescência começa com a puberdade e que é uma fase da vida do sujeito. Neste caso, aproximam-se daquelas colocadas por nossos referenciais, como Pereira (2005); Calligaris (2000), dentre outros. Entretanto, há considerável discrepância entre os professores acerca de quando ela acaba. Há desde pessoas que cravam uma idade precisa (21 anos, que era a antiga idade para o sujeito se responsabilizar juridicamente pelos seus $\operatorname{atos}^{8}$ e que, no caso da professora em questão, também foi a idade com que concluiu a graduação), até falas que evidenciam a complexidade em delimitar o início e o fim deste período, constituindo-se em um processo intenso, com diversas experimentações. Essa percepção se aproxima dos referidos referenciais teóricos já mencionados (é o caso da fala de Elizabeth revelado no quadro anterior).

Outras se aproximam dos nossos referenciais também quando compreendem o reconhecimento da adolescência pela negação daquilo que o sujeito não é, ou seja, ele é reconhecido como adolescente por não ser uma criança e, tampouco, por não ser um adulto. Para exemplificar esse fato, destacamos as frases de Flávio e Micheli no quadro anterior. Essas afirmações se assemelham àquela proferida por Pereira (2005) ao afirmar que o adolescente acaba por ter um papel social indefinido diante dessa dúvida (não é mais criança, mas também não é mais adulto), ou com a afirmação de Calligaris (2000), que coloca essa dificuldade social em reconhecer o adolescente pelas suas características próprias - seu reconhecimento se faz pela afirmação do que ele não é. Nessa mesma linha de pensamento, também verificamos afirmações como a de Elizabeth que explicitam a crise de identidade na adolescência presente em todos os autores que estudam o tema:

${ }^{8}$ De acordo com Eluf (2003), o Código Civil de 1916 estabelecia que a menoridade cessava aos 21 anos. 
DOI: https://doi.org/10.33238/ReBECEM.2021.v.5.n.1.26083

"Eu acho que é uma busca, né (sic)? Uma busca por uma identidade. Então ele (o adolescente) vai muitas vezes testar várias coisas".

\subsection{Sobre haver uma personalidade única para adolescentes}

Nossos referenciais adotados apontam para um mosaico de diferentes personalidades que compõem os adolescentes, embora haja, em comum, a crise de identidade, vivenciada de modo distinto por cada um deles. Ao analisarmos as falas dos professores, podemos verificar, também, eventuais estereótipos atribuídos aos que estão na adolescência - os quais são denunciados de forma veemente por Calligaris (2000), quando este afirma que eles são profundamente discriminados socialmente. Segue o quadro:

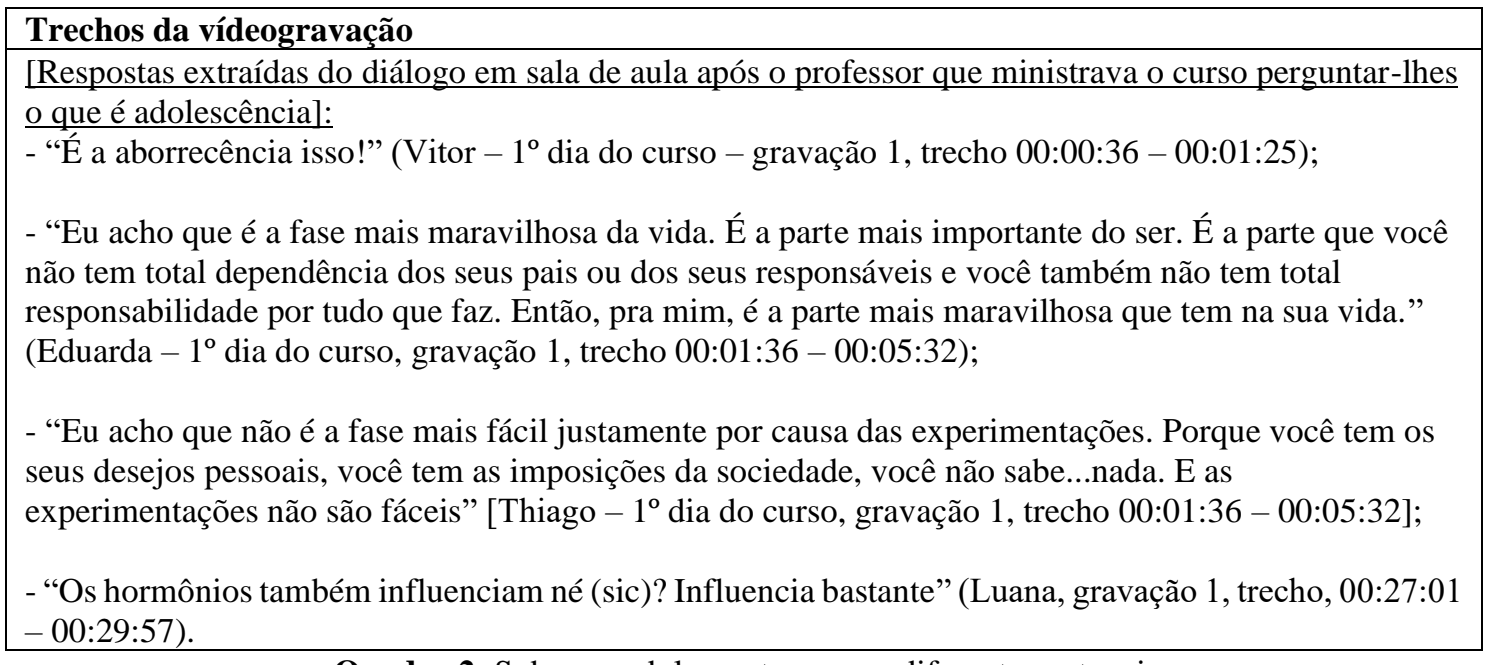

Quadro 2: Sobre os adolescentes serem diferentes entre si.

Fonte: Elaborado pelos autores com base nas videogravações. 2019.

De forma geral, há algumas falas que remetem à percepção de senso comum sobre adolescência. No termo "aborrecência”, que Vitor expressa no Quadro 2, é possível identificarmos umas dessas representações. A palavra, de caráter estereotipado, vem de uma aglutinação das palavras adolescência com aborrecer, ou seja, o adolescente seria uma pessoa desobediente, inquieta, que irrita aos próximos. Contudo, conforme aponta Amaral (2006), estereotipar o adolescente traz grandes riscos, pois, segundo Oliveira (2015), é preciso considerá-lo como sujeito histórico, social, cultural, que tem gostos e identidades próprias, sem generalizá-los. Eduarda traz a adolescência como um ideal de felicidade -"Eu acho que é a fase mais maravilhosa da vida" e afirma, em seguida, que: "você também não tem total responsabilidade por tudo que faz. Então, para mim, é a parte 


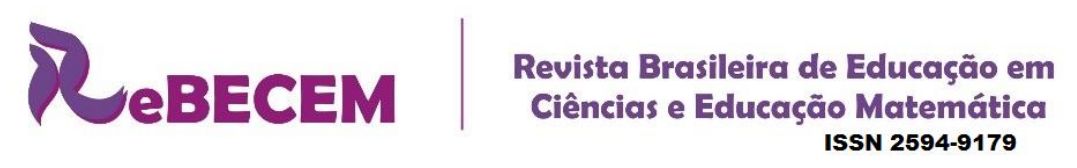

DOI: https://doi.org/10.33238/ReBECEM.2021.v.5.n.1.26083

mais maravilhosa que tem na sua vida”. Calligaris (2000) afirma que o adolescente vive um paradoxo por ser frustrado por conta de uma moratória forçada (sem trabalho, sem poder viver a vida afetiva e sexual em sua plenitude, mesmo o corpo sendo biologicamente adequado para tal), ao mesmo tempo em que há uma idealização social que os obriga a se sentirem felizes.

Também podemos observar, como apresentado por Moscovici (2015), afirmações com forte relação com termos científicos (a ciência como geradora de representações sociais), como a colocada por Luana. Realmente, como bem compreendemos e como colocado pela ciência, é na adolescência que ocorre um pico da liberação dos hormônios sexuais - o que acarreta novos desafios e experimentações no campo da sexualidade e da afetividade, além das implicações de mudança na auto-imagem pelo adolescente. Entretanto, muitas vezes, reduz-se a complexidade do período da adolescência a uma leitura exclusivamente biológica condicionada por mudanças fisiológicas decorrentes desses hormônios, sexualizando-o em demasia - como se hormônios e sexualidade não fossem fundamentais em todas as idades da vida de uma pessoa. Ademais, a pesquisadora Herculano-Houzel (2005), um dos referenciais utilizados, mostra que essa parte hormonal não é formada durante a adolescência - é apenas liberada nesta fase da vida. Para os referenciais adotados, a adolescência não está relacionada somente à parte biológica, mas é influenciada por fatores históricos, sociais, psicológicos e culturais.

\subsection{Sobre as regras e limites na adolescência}

Nossos referenciais (GUTIERRA, 2003; SILVA, 2008) apontam para a absoluta necessidade de regras/lei/papel do pai para os adolescentes se sentirem mais seguros e tranquilos, inclusive para tentarem burlá-las, desde que essas regras sejam poucas, claras e bem discutidas com eles. Pode ser extremamente nocivo o fato de elas não existirem ou de serem frequentemente burladas pelos adultos, a despeito dos discursos em contrário. Neste caso, pode-se comprometer a imagem do mundo adulto frente a eles, gerando-lhes insegurança e agravamento da conhecida desconfiança do mundo adulto. Por outro lado, esses mesmos referenciais mostram o quanto há de permissão - e quase uma cobrança social - para que esses adolescentes descumpram as regras e transgridam, pois, estão na fase da vida em que isso é esperado.

A seguir, vemos o quanto nossos professores se aproximavam ou não dessa percepção. 


\begin{abstract}
Trechos da vídeogravação
No segundo dia do curso o professor ministrador abriu uma discussão sobre a parte final do livro de Beatriz Cauduro Cruz Gutierra: “Adolescência, Psicanálise e inclusão - o mestre 'possível' de adolescentes" e um dos participantes opinou sobre a parte em que a autora do livro discuti as regras]: - "Eu achei curioso porque fala disso [sobre regras] é uma coisa bacana...eu acho que o sucesso disso não dá pelo...por chegar e falar: "eu exijo ser chamada de senhora", mas se dá porque o respeito é dado a partir do momento que ele ouve o aluno que é uma relação horizontal. Eu acho que... pode ser que eu tenha dado uma leitura errada..” [Thiago - gravação 2, trecho 00:00:19 - 00:01:22];

[Ainda no mesmo trecho do livro especificado anteriormente, Angélica explica a ideia do adolescente ser considerado um transgressor, afirmando que isso é um acordo não explicito na relação professoraluno. Com isso, explica também a importância da afetividade, das regras em tal relação]:

- "E esses acordos, essas regras muitas vezes são estabelecidas não...de maneira objetiva né (sic)? Muitas vezes esses acordos não são nem externados." (Angélica, $2^{\circ}$ dia do curso, Gravação 2, Trecho: 00:08:46-00:12:08);

- "E no momento que você entra em contato ele percebe que ele é...você tem essa afetividade...você acaba se aproximando dele e é nesse aproximar que você estabelece essas regras [...].”(Angélica, $2^{\circ}$ dia do curso, Gravação 2, 00:08:46 - 00:12:08).
\end{abstract}

Quadro 3: Sobre a importância das regras/leis e a permissão para as transgressões.

Fonte: Elaborado pelos autores com base nas videogravações.

As frases acima se assemelham às discussões da ciência (universo reificado) com relação à importância das regras ou das leis na adolescência. De acordo com os referenciais (SILVA, 2008, 2013; GUTIERRA, 2003; AMARAL, 2006), uma sociedade, que é marcada profundamente pela busca do imediato, pela rapidez, pelo hedonismo e pelo narcisismo ${ }^{9}$, pode encontrar um contraponto em referências sólidas que ajudem seus adolescentes a enfrentarem tais elementos, com a questão das regras e das leis e, para tanto, é importante que esses saibam a sua importância, inclusive da disciplina, para conseguirem seus objetivos - quaisquer que sejam. Neste sentido, a ciência, disciplinadora e rigorosa, pode ser um importante instrumento para aprimorar o processo educativo (SILVA, 2013). Entretanto, Angélica nos traz uma ideia muito interessante de que o adolescente aprende mais pelo processo simbólico/imaginário do que pela fala: "E esses acordos, essas regras muitas vezes são estabelecidas não... de maneira objetiva, né (sic)? Muitas vezes esses acordos não são nem externados", concordando com muitos de nossos referenciais, como Gutierra (2003, p. 126): “A partir do valor simbólico atribuído ao lugar de mestre, observamos que os entrevistados conseguem exercer a função de sustentar a lei e o dever na relação educativa [...]”.

Outras falas, como a de Angélica, também se assemelham aos dos nossos referenciais quando afirmam que o cumprimento ou a delimitação de regras parecem ter

\footnotetext{
${ }^{9}$ Elementos presentes na sociedade pós-moderna, de acordo com autores utilizados no curso de extensão: Lipovestky (2005), Bauman (1998) e Amaral (2006).
} 


\section{Revista Brasileira de Educação em \\ Ciências e Educação Matemática \\ ISSN 2594-9179}

DOI: https://doi.org/10.33238/ReBECEM.2021.v.5.n.1.26083

maior eficiência quando colocadas para melhorar a aprendizagem e o ambiente de todos, não sendo uma mera forma de submeter os alunos ao narcisismo do professor (GUTIERRA, 2003, p. 82), além de ser uma consequência da afetividade existente na relação: "E no momento que você entra em contato ele percebe que ele é...você tem essa afetividade...você acaba se aproximando dele e é nesse aproximar que você estabelece essas regras [...]". Certamente, como afirma Amaral (2017), o afeto nessa relação, em uma sociedade que, segundo Lipovetsky (2005), não tem bases emocionais estáveis, será uma forma de minimizar alguns atritos e estabelecer regras de uma maneira dialógica.

Percebemos divergência em relação ao que afirmam os referenciais sobre a importância das regras no momento em que um dos professores se incomodou com a discussão da necessidade de regras por acreditar que elas supostamente vão contrariamente à ideia de horizontalidade expressa na sua visão de educação. Mesmo com o professor responsável pelo curso afirmando que essas regras deveriam ser feitas para todos - e não apenas para os alunos -, o professor em questão incomodou-se, atribuindo a essa fala uma permissão para que o professor de adolescente aja com autoritarismo. Nota-se, aqui, certa confusão entre o que é autoridade e autoritarismo.

\subsection{Sobre ser professor de adolescentes}

Alguns dos referenciais que adotamos explicitam a necessidade do professor de fundamental II e de ensino médio ser reconhecido como "professor de adolescentes" - e não apenas como um professor de uma área do conhecimento (SILVA, 2008; SILVA; FORATO, 2017). Neste sentido, devem ser "sensíveis às causas adolescentes", abrindo “[...] espaço para que elas sejam discutidas em alguns momentos das aulas, sem, no entanto, abrirem mão do lugar do mestre e de sua função como responsável pela transmissão dos conteúdos formais" (GUTIERRA 2003, p.132). Além disso, sendo professores, conseguem identificar-se com as características adolescentes e desejam, de fato, promover melhorias na vida do sujeito que ensina.

Veremos como esses elementos estiveram presentes nas falas iniciais dos professores.

Trechos da vídeogravação

[Neste momento o professor responsável pelo curso pergunta se alguém se define como professor de adolescente e ninguém levanta a mão. É possível apenas ouvir ao fundo Angélica dizendo que gosta de adolescentes - o que é diferente de se definir como professora de adolescentes. Em seguida Elizabeth responde]: 
DOI: https://doi.org/10.33238/ReBECEM.2021.v.5.n.1.26083

- "Não, eu falo: "sou professora." Se perguntarem... sou professora de biologia e ciências. Porque em algumas instituições que eu trabalhei eles começaram a tratar a gente com muito respeito nesse sentido. Agora... eles falam: "vamos homenagear os professores." E isso começou a... a ser importante pra (sic) mim. Aí hoje eu falo: ‘eu sou professora'.” (1º dia de curso, Gravação 3, Trecho: 00:17:43 - 00:18:59);

[Quando o professor que ministrava o curso abriu uma discussão sobre a parte final do livro da Beatriz Cauduro Cruz Gutierra: "Adolescência, Psicanálise e inclusão - o mestre 'possível' de adolescentes”, Arthur levantou um ponto de discordância com a autora:

- "E...é um ponto que eu gostaria de colocar: será que...é...uma boa ideia...uma boa ideia você jogar 'na lata' que (sic) e...não sei? Porque o adolescente pode interpretar isso de uma maneira diferente [Jaqueline a todo o momento olha fixamente para Arthur e balança a cabeça de modo afirmativo]." (2 $2^{\circ}$ ia de curso, Gravação 1, Trecho: 00:03:58 - 00:10:32).

- "Eu acho também que é que...na nossa discussão ficou clara que o professor também é...espaço né (sic) Tem que... [...] eu acho que ao invés do professor chegar lá na frente querer ser o interessante, ele tem que ser interessado no aluno, entendeu?" (Flávio, $2^{\circ}$ dia do curso, Gravação 4, trecho, 00:12:04 00:13:19).

Eu acho assim que...essa coisa de você é...colocar pro (sic) aluno que você não sabe tudo eu acho que tem a ver com essa questão do vínculo[...]”). Angélica, 2.o. dia do curso, Gravação 4, trecho, 00:12:04 $-00: 13: 36)$.

Quadro 4: Sobre ser professor de adolescentes.

Fonte: Elaborado pelos autores com base nas videogravações. 2019.

Apesar da insistência do professor que ministrava o curso perguntando se ela se considera uma "professora de adolescentes", Elizabeth não se assumia como professora de adolescentes - apenas como professora de biologia: "Não, eu falo: "sou professora". Se perguntarem... sou professora de biologia e ciências". Aliás, os demais membros da turma também não parecem se reconhecer, de imediato, como professores de adolescentes, já que houve um silêncio significativo diante da pergunta feita pelo professor do curso. No momento em que era discutido um texto de Gutierra (2003), destacando que o professor de adolescentes deve mostrar-se como alguém "não sabendo de tudo", Jaqueline demonstrou uma preocupação com um possível descrédito do professor que dizia não saber de um assunto: "será que...é...uma boa ideia...uma boa ideia você jogar na lata que...não sei?", demonstrando desconhecer os riscos da construção de uma imagem irreal para os adolescentes. Afinal, conforme nos aponta Gutierra (2003, p.94), o "bom professor" não é aquele que se coloca na posição de "todo saber”, mas é o que "consegue, por meio de seu estilo próprio, acionar o desejo de saber do aluno [...] permitindo que ele se envolva e se implique como desejante". A autora coloca que: "o mestre deve estar numa posição de crença de que aquilo que transmite é importante" (p.96) e que "adolescentes que sabem da impossibilidade de completude são 'cruéis' com os mestres que se apresentam como 'todo'” (p.135). Gutierra (2003) defende a "circulação discursiva" (p.134), ou seja, que o professor não se coloque como detentor 


\section{$7) \quad$ Revista Brasileira de Educação em \\ Ciências e Educação Matemática \\ ISSN 2594-9179}

DOI: https://doi.org/10.33238/ReBECEM.2021.v.5.n.1.26083

exclusivo dos conhecimentos sem dar espaço para os alunos também se colocarem no processo de ensino-aprendizagem.

Por outro lado, percebemos que Flávio, corrobora com essas ideias defendidas pela autora: "o professor também é ... espaço né (sic) Tem que... [...] eu acho que ao invés do professor chegar lá na frente, querer ser o interessante, ele tem que ser interessado no aluno, entendeu?". Angélica fala da importância do vínculo para que a aprendizagem possa ocorrer: "Eu acho assim que...essa coisa de você é...colocar pro (sic) aluno que você não sabe tudo eu acho que tem a ver com essa questão do vínculo[...]". Ideia muito disseminada por Amaral (2006), por exemplo, que explica a importância do professor estar atento aos afetos presentes nesse processo (de aprendizagem) e ao acolhimento.

Aqui, cabe ressaltar que esses professores já se mostram diferenciados em relação aos demais exatamente por escolherem fazer esse curso. Assim, são sujeitos que, a priori, poderiam ser colocados como mais sensíveis às causas adolescentes. Mesmo assim, demonstraram dificuldades em se reconhecerem como tal, ainda que tenham percebido em alguns casos pela própria prática, noutros por leituras - a importância de constituírem vínculos e de contemplarem espaços para as questões adolescentes em seu trabalho.

\subsection{Sobre ser professor de ciências para adolescentes}

Os referenciais que adotamos sugerem que a ciência deva ser colocada a serviço das questões adolescentes, seja buscando formas de dialogar melhor com esse público (SILVA, 2008, 2011; SILVA; FORATO, 2017), seja criando perspectivas de horizontes profissionais e de projeto de vida a partir da ciência (SOUZA, 2015). Os referenciais que adotamos também afirmam que, em algumas situações, a ciência pode não ser muito efetiva para a discussão de adolescência - e que não há nada de errado em relação a isso (SILVA, 2008).

O quadro a seguir apresenta algumas afirmações feitas pelos participantes nos momentos iniciais em que era discutido o papel do ensino de ciências para os adolescentes.

\section{Trechos da vídeogravação}

[Em um momento em que o professor que ministrava o curso perguntava o que os professores aprenderam no encontro passado]:

Eu fiquei pensando...fiquei um pouquinho introspectivo agora e...pensando...o (estendendo a voz)...trabalho do professor de adolescentes envolve o equilíbrio entre afeto e a parte tecnicista (gesticula colocando a palavra tecnicista entre aspas). (Arthur, Gravação 4, Trecho: 00:09:28 00:11:56). 
DOI: https://doi.org/10.33238/ReBECEM.2021.v.5.n.1.26083

[Nesse momento os professores começam a discutir alguns textos disponibilizados com antecedência por e-mail, com base em algumas questões norteadoras elaboradas pelo professor que ministrava $\mathrm{o}$ curso. Nessa discussão, Eduarda pergunta qual foi a reação dos professores de química, física e biologia ao saber que sua contribuição foi pouca para a discussão de adolescência (este texto em questão, narrava um projeto sobre adolescência realizado em uma escola pública paulista). Percebe-se que a professora, (pela entonação de sua voz) fica um pouco preocupada com esse detalhe - o de não contribuir ou contribuir pouco para com o assunto]:

Professor: Eu acho que quem acha que química, física e biologia vai resolver até essas questões de cabeça não sabe a matéria. (Segundos de silêncio). De verdade!

Eduarda: O professor...

Professor: De verdade! De verdade! Eu acho que não domina o conhecimento.

Eduarda (com um tom de indagação): Quando um aluno, o aluno falou isso, que aprendeu melhor na filosofia, o que o professor da...das exatas pensou?

Professor: Bom...

Eduarda: Teve esse questionamento? [Eduarda - $3^{\circ}$ dia do curso, Gravação 4, trecho 00:00:44 00:02:44].

Quadro 5: Um ensino de ciências para adolescentes.

Fonte: Elaborado pelos autores com base nas videogravações, 2019.

A primeira fala revela uma constatação de que o ensino de ciências parece pouco atrativo, à primeira vista, aos adolescentes. De fato, se tal ensino for imposto como um conjunto de conhecimentos técnicos, desprovidos de significados, certamente essa primeira impressão fará sentido, conforme apontam alguns dos nossos referenciais (AMARAL, 2017). Além disso, os trechos das falas revelam dificuldade do professor especialista em uma determinada área em considerá-la como não central em algumas situações da vida escolar - algo que já foi constatado em trabalhos sobre adolescência na escola (SILVA, 2008). Por outro lado, também há indícios do reconhecimento das ciências como um conhecimento técnico em que há muitas dificuldades em descobrir afetos e atrativos ao ser ensinado. No outro fragmento do quadro, fica nítida a separação que Arthur faz entre o que ele chama de conteúdos técnicos e o afeto, como se este último não fizesse parte da técnica no trabalho de ensino com adolescentes, discordando, portanto, do que afirmam diversos autores como Amaral (2006) ${ }^{10}$.

\subsection{A produção dos professores}

Ao final do curso, foi solicitado a todos os professores que realizassem uma sequência didática ou um projeto juvenil que incluísse as questões discutidas ao longo do curso nos conteúdos de ciências. Isso foi feito de modo para que conseguíssemos

\footnotetext{
10 "Para se compreender o mal-estar das escolas, não se pode negar que o campo intrincado da constituição do sujeito humano faz parte dos processos socializadores a que estão sujeitos professores e alunos, daí a importância de se considerar a participação dos afetos no desenvolvimento da capacidade de pensar e de se relacionar com o saber, assim como do próprio ato de transmitir o conhecimento". (AMARAL, 2006, p.80).
} 
DOI: https://doi.org/10.33238/ReBECEM.2021.v.5.n.1.26083

compreendermos um pouco mais sobre a percepção do papel das ciências juntamente aos adolescentes quando fôssemos analisar as sequências didáticas ou os projetos juvenis propostos pelos participantes. É importante destacar que essas tarefas já foram construídas após a leitura e as discussões nos encontros, de modo que já era possível apresentar alguma influência da vivência no curso. Entretanto, como não é o objetivo central desta pesquisa analisar os impactos específicos do curso, analisamos as sequências tendo em vista as possíveis reminiscências das percepções de adolescência que os professores já carregavam consigo nos inícios das discussões de cada encontro.

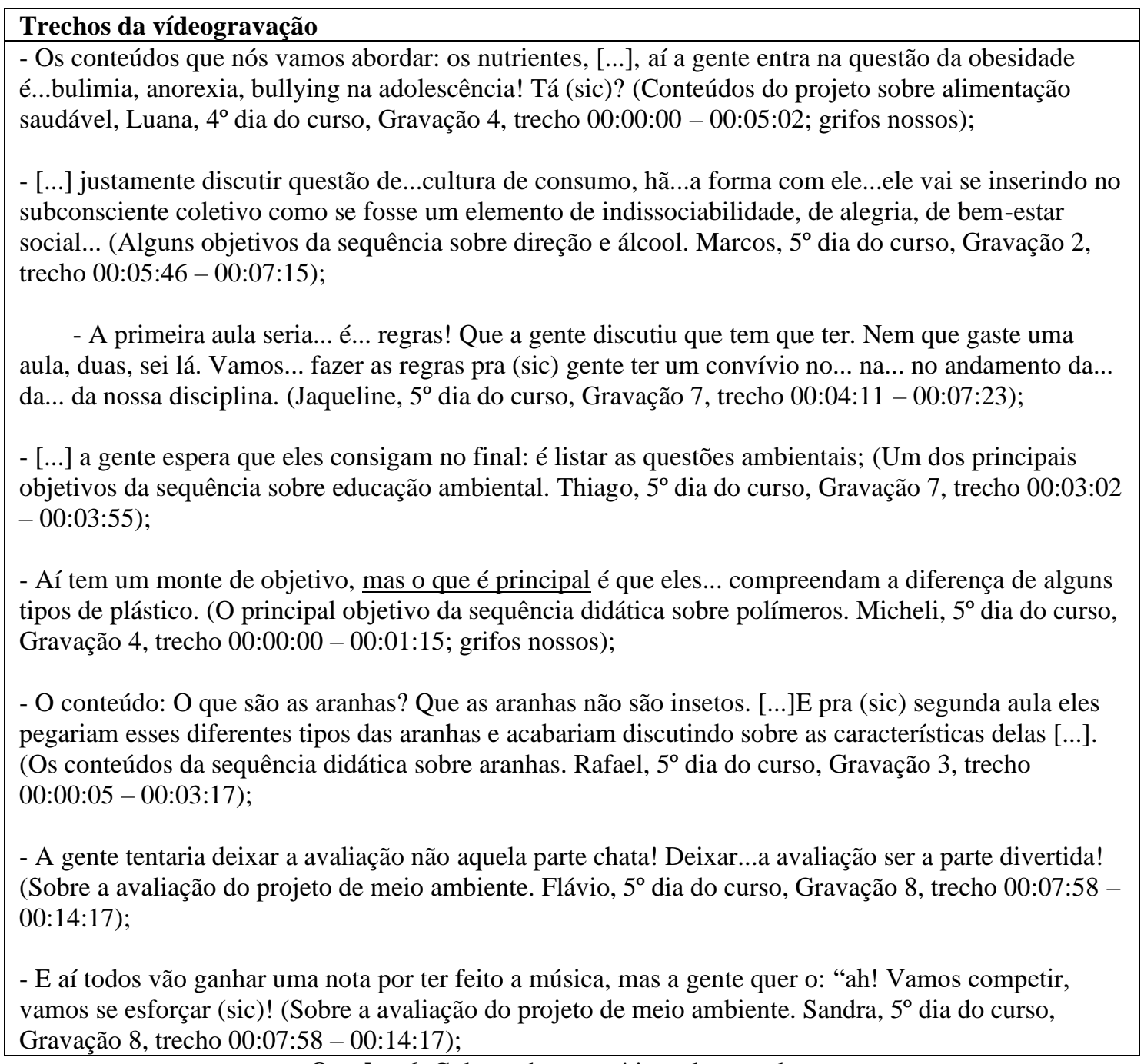

Quadro 6: Colocando em prática: alguns relatos.

Fonte: Elaborado pelos autores com base nas videogravações, 2019.

Diante do exposto no quadro acima, percebe-se que os conteúdos da sequência construída por Luana e Katia são um exemplo de grande aproximação das discussões realizadas em sala no curso. As professoras incluíram questões sobre os padrões que são feitos pela sociedade atual, principalmente os relacionados à estética. Acreditamos que 


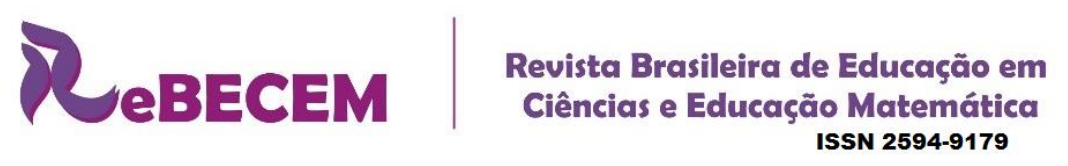

DOI: https://doi.org/10.33238/ReBECEM.2021.v.5.n.1.26083

discutir essas questões é importante, uma vez que esses padrões, impostos pela sociedade, segundo Bauman (1998), geram angústias. Também acreditamos que isso abarque a questão da singularidade dos adolescentes (SILVA, 2013), já que são diferentes entre si.

Outra sequência que mereceu destaque foi a de Paulo e Marcos, que evidenciou a crítica ao consumo como sinônimo de status, assim como aponta Bauman (1998), dimensionando com isso, não só conceitos científicos da questão do álcool e da direção, mas também aspectos sociais, culturais e históricos, como proposto por Silva (2011) e pelos próprios documentos oficiais como os PCN (Parâmetro Curricular Nacional; BRASIL, 1998). No trabalho de Jaqueline e Thiago, constatamos que havia uma tentativa de discussão de regras, ainda que isoladas: na proposta, havia uma atividade específica no início da sequência didática que ocupava duas aulas unicamente para a discussão da importância das regras; essas aulas não dialogavam com a parte do conteúdo científico propriamente dito, evidenciando uma dificuldade na compreensão de que tais questões devem permear todos os momentos: “A primeira aula seria... é... regras! [...] a gente iniciaria a aula de ciências mesmo com a questão é... ambiental". Além disso, não colocaram a aprendizagem de tais regras como objetivos da sequência: "a gente espera que eles consigam no final: (sic) é listar as questões ambientais". O mesmo acontece no trabalho da professora Micheli, que priorizava os conteúdos científicos em seu objetivo: “Aí tem um monte de objetivo, mas o que é principal é que eles... compreendam a diferença de alguns tipos de plásticos" [grifos nossos]. E também na sequência didática de Rafael e Adriana, em que, neste caso, não havia nem a tentativa de discussão sobre adolescência, somente dos conteúdos (no caso, aspectos ligados à biologia das aranhas). O projeto do grupo de professores constituído por Flávio, Arthur e Sandra, incentivava a competição e a revanche entre os adolescentes, como se essa medida fosse necessariamente atraente para os adolescentes, desconsiderando que a competição excessiva não necessariamente tem trazido benefícios à sociedade - e que as escolas devem atuar contrariamente a isso, na opinião de alguns dos nossos referenciais (SILVA, 2008).

Houve uma avaliação sobre o curso feita pelos participantes ao final, na forma de questionários, na qual os professores, em sua maioria, mostraram-se satisfeitos com a abordagem do tema e apontaram a necessidade de um tempo maior para a discussão do assunto. 


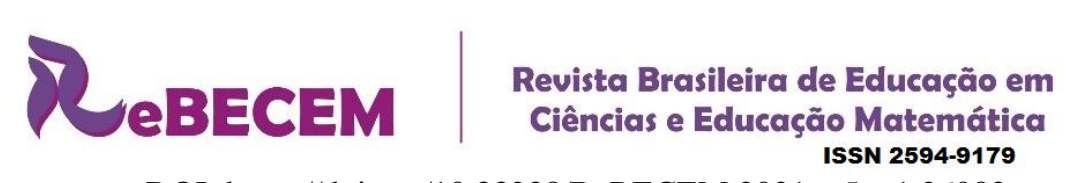

DOI: https://doi.org/10.33238/ReBECEM.2021.v.5.n.1.26083

\section{Considerações finais}

Esta pesquisa pretendeu mapear as percepções de adolescência de professores de ciências. Percebemos que os professores apresentam uma percepção de adolescência com elementos do senso comum, em que há uma generalização no sentido de biologizar o adolescente (serem mais sexualizados que os adultos, influenciados por hormônios etc.) e também de viverem a fase mais feliz da vida, em que as transgressões lhes são permitidas pelos adultos. Também aparece a percepção do adolescente competidor, irresponsável e que só quer se divertir. Por outro lado, mesmo durante o curso, havia também consideráveis aproximações dessa percepção de adolescência com aquela proposta por nossos referenciais, notadamente como sendo a compreensão de um período complexo e sem previsão de término, iniciado na puberdade, fortemente influenciado por elementos afetivos, com mudanças físicas e psicológicas e seguidas experimentações de papéis. Os professores também revelaram certa sensibilidade para a compreensão do afeto como central no processo de ensino-aprendizagem dos estudantes, ainda que tal percepção lhes parecesse como resultado de sua ação pedagógica e não de conhecimento gerado pelos estudiosos sobre o tema. Ao longo do curso, notamos que pareceu ter havido um relativo avanço do senso comum em direção ao conhecimento reificado, conforme prevê o complexo processo proposto pela TRS. Também percebemos que os professores participantes desta pesquisa trouxeram consigo em suas falas as vivências e as experiências cotidianas que ora se aproximaram e ora se distanciaram dos referenciais teóricos.

No caso do ensino de ciências, um tanto mais voltado para discussões metodológicas, este trabalho buscou trazer novos elementos para serem discutidos nas propostas de ensino, revelando possibilidades de o professor de ciências enxergar-se como professor de adolescentes e incorporar essa identidade à sua prática, algo que pareceu distante entre os participantes da pesquisa. Entendemos que mais ações com este objetivo são necessárias, não apenas em cursos de formação continuada de professores, mas também na formação inicial.

Por fim, salientamos que há várias maneiras de serem analisados os dados aqui apresentados e isto é uma característica deste tipo de pesquisa. Afinal, a própria adolescência é histórica e culturalmente construída e, por isso, múltipla - o que permite 
diferentes considerações. Entretanto, mesmo que modesta, acreditamos que nossa contribuição esteja dada.

\section{Referências}

AMARAL, M. A estética transgressora do rap e do funk: em direção à reversão dialética da educação pública nas metrópoles brasileiras. In. AMARAL, M. \& SOUZA, M.C.C. Educação Pública nas metrólores brasileiras. São Paulo: Paco Editorial/Edusp, 2017, p.279-300.

AMARAL, M. Encontros com professores de uma escola estadual do Ensino Médio - uma escuta em que a dimensão objetiva se vê alinhavada pela subjetividade dos autores. In: AMARAL, M. (Org.). Educação, psicanálise e direito: combinações possíveis para se pensar a adolescência na atualidade. São Paulo: Casa do Psicólogo, 2006. p. 75-96.

ANDRÉ, M; LÜDKE, M. Pesquisa em educação: Abordagens qualitativas. São Paulo: EPU, 1986.

ANDRÉ, M. - Etnografia da prática escolar. 10ª Edição. Campinas: Papirus, 1995.

ANDRÉ, M. O cotidiano escolar: um campo de estudo. In: ANDRÉ, M. et al. O coordenador pedagógico e o cotidiano da escola. 5. ed. São Paulo: Loyola, 2003. p. 9-19.

ARIÉS, P. História Social da Criança e da Família. 2. ed. Tradução de Dora Flaksman. Rio de Janeiro: LTC Editora, 1981.

BAUMAN, Z. O mal-estar da pós-modernidade. Rio de Janeiro: Zahar, 1998. 276p.

BRASIL. Ministério da Educação. Secretária de Educação Fundamental. Parâmetros Curriculares Nacionais: terceiro e quarto ciclos: ciências naturais. Secretária de Educação Fundamental. Brasília: MEC/ SEF, 1998. Disponível em:

<http://portal.mec.gov.br/seb/arquivos/pdf/ciencias.pdf>. Acesso em: 15 mar. 2016.

CALLIGARIS, C. A adolescência. São Paulo: Publifolha, 2000.

CARNEIRO, M. Os projetos juvenis na escola de Ensino Médio. Brasília, DF: Instituto Interdisciplinar, 2001. $160 \mathrm{p}$.

CRUSOÉ, N. M. de C. A teoria das representações sociais em Moscovici e sua importância para a pesquisa em educação. APRENDER - Cad. de Filosofia e Pisc. da Educação. Vitória da 
DOI: https://doi.org/10.33238/ReBECEM.2021.v.5.n.1.26083

Conquista, Ano II, n. 2, p. 105-114, 2004. Disponível em:

<http://periodicos.uesb.br/index.php/aprender/article/viewFile/3792/pdf_121>. Acesso em: 14 jul. 2017.

ELUF, L.N. A nova maioridade civil e os benefícios penais para menores de 21. 2003.

Disponível em: <https://www.conjur.com.br/2003-abr-

30/maioridade_civil_legislacao_penal_brasileira>. Acesso em 14 de setembro de 2020.

GUTIERRA, B.C.C. Adolescência, Psicanálise e Educação: o mestre-possível de adolescente, São Paulo: Ed. Avercamp, 2003. 149p.

HABERMAS, J. O discurso filosófico da modernidade. São Paulo: Martins Fontes, 2002. $350 \mathrm{p}$.

HERCULANO-HOUZEL, S. O cérebro em transformação. Rio de Janeiro: Objetiva, 2005. $224 \mathrm{p}$.

LIMA, F. H. Um método de transcrições e análise de vídeos: a evolução de uma estratégia. In: Encontro Mineiro de Educação Matemática, 7, 2015, São João Del Rei. Anais... São João Del Rei: Universidade Federal de São João Del Rei, 2015. v. 7. p. 1-11. Disponível em: <https://doi.org/10.5216/rpp.v19i4.42263>. Acesso em: 27 jun.2017.

LIPOVESKY, G. A Era do Vazio: ensaios sobre o individualismo contemporâneo. Tradução: Therezinha Monteiro Deutsch. Barueri, SP: Manole, 2005, 200p.

LUDWIG, A. C. W. Métodos de Pesquisa de Educação. Educação em Revista, UFMG: Belo Horizonte v. 15, n. 2, p.7-32, 2014. Disponível em:

<http://periodicos.ufpb.br/index.php/rteo/article/view/18881/12572>. Acesso em: 18 dez. 2017.

MARCONDES, T. e SILVA, J.A. O ensino de ciências na educação: o caso da sexualidade para adolescentes com deficiência intelectual. In: Encontro Nacional de Pesquisa em Educação em Ciências (XI ENPEC), 2017, Florianópolis. Anais... Santa Catarina, 2017, 9p. Disponível em: <http://www.abrapecnet.org.br/enpec/xienpec/anais/resumos/R0801-1.pdf >. Acesso em: 30 março 2021.

MATOS, D.; JARDILINO, J. R. Os conceitos de concepção, percepção, representação e crença no campo educacional: similaridades, diferenças e implicações para a pesquisa. Educação \& Formação, Fortaleza, v. 1, n. 3, p. 20-31, 2016. Disponível em:

<https://revistas.uece.br/index.php/redufor/article/view/111>. Acesso em: 25 set. 2020.

MOSCOVICI, S. Das representações coletivas às representações sociais: elementos para uma história. In: JODELET, D. (Org.). As representações sociais. Rio de Janeiro: Ed. da UERJ, 2001. p. 18-66. 
DOI: https://doi.org/10.33238/ReBECEM.2021.v.5.n.1.26083

MOSCOVICI, S. O fenômeno das representações sociais. In: MOSCOVICI, S. Representações sociais: investigações em psicologia social. Tradução de. Pedrinho A. Guareschi. 11. ed. Petrópolis, RJ: Vozes, 2015, p. 29 - 110.

OLIVEIRA, E. N. Adolescência e física: experiências dos bolsistas do Pibid em uma escola pública do município de Diadema. 2015. 75 f. Trabalho de conclusão de curso. Unifesp: Diadema, 2015.

PEREIRA, A.C.A. O adolescente em desenvolvimento. São Paulo: Harbra, 2005. 155p.

SILVA, J.A.; FORATO, T.C.M. As contribuições do subprojeto Pibid-Física para a formação inicial e continuada de professores tendo em vista a tarefa de educar o adolescente em tempos de sociedade pós-industrial. In: PRADO, J. Desafios da formação inicial docente no contexto do Pibid: experiências de formação de professores nos arrabaldes das cidades de Diadema e Guarulhos (SP). São Paulo: Paco Editorial, 2017. p. 97-116.

SILVA, J.A. A inclusão do tema adolescência no Ensino Médio: contribuições e limitações das ciências em uma proposta interdisciplinar de uma escola pública. In: ENCONTRO NACIONAL DE PESQUISA EM EDUCAÇÃO EM ENSINO DE CIÊNCIAS, 8, 2011, Campinas. Anais... Campinas. ABRAPEC, 2011, 11p. Disponível em:

<http://www.nutes.ufrj.br/abrapec/viiienpec/resumos/R0766-1.pdf>. Acesso em: 08 jan. 2017.

SILVA, J.A. As possíveis contribuições do ensino de ciências para a identidade do Ensino Fundamental II e para a tarefa de alfabetizar. Ciênc. educ., Bauru, v. 19, n. 4, p. 811-821, 2013. Disponível em:

<http://www.scielo.br/scielo.php?script=sci_arttext\&pid=S151673132013000400003\&lng=en\& nrm=iso $>$. Acesso em: 08 jan. 2017.

SILVA, J.A. Compromisso e paixão: o universal e o singular na boa escola pública. 2008. 339 f. Tese (Doutorado em Educação) - Faculdade de Educação da Universidade de São Paulo, São Paulo, 2008. Disponível em:

$<$ http://www.teses.usp.br/index.php?option=com_jumi\&fileid=12\&Itemid=77\&lang=ptbr\&filtro=Silva,\%20Jose\%20Alves\%20da $>$. Acesso em: 21 mar. 2015.

SOUZA, L.C. A influência da relação professor-aluno- conhecimento na aprendizagem de estudantes e na escolha de seus projetos de vida relacionados às ciências. $2015,59 \mathrm{f}$.

Trabalho de final de curso - Ciências-Licenciatura. Diadema: Unifesp, 2015.

ZABALA, A. A prática educativa: como ensinar. São Paulo. Porto Alegre: Artmed, 1998. $224 \mathrm{p}$.

Recebido em: 14 de outubro de 2020

Aceito em: 05 de abril de 2021 